\title{
Traumatic Brachial Plexus Injury in Indonesia: An Experience from a Developing Country
}

\author{
Heri Suroto, MD, $\mathrm{PhD}^{1}$ Irene Antoni, $\mathrm{MD}^{2}$ Angelina Siyo, $\mathrm{MD}^{2}$ Tawatha C. Steendam, $\mathrm{MD}^{3}$ \\ Tabita Prajasari, MD ${ }^{1}$ Herlambang Budi Mulyono, MD ${ }^{4}$ Brigita De Vega, MD, MSc ${ }^{2,5}$
}

\footnotetext{
1 Department of Orthopaedic and Traumatology, Dr Soetomo General Academic Hospital/ Faculty of Medicine Universitas Airlangga, Surabaya, Indonesia

2 Research Fellow at Cell and Tissue Bank Regenerative Medicine, Dr. Soetomo General Academic Hospital, Surabaya, Indonesia

${ }^{3}$ Leiden University Medical Centre, The Netherlands

${ }^{4}$ Faculty of Medicine Universitas Cendrawasih, Jayapura/ Papua, Indonesia
}

\begin{abstract}
Address for correspondence Heri Suroto, MD, PhD, Departement of Orthopaedic and Traumatology, Dr Soetomo General Academic Hospital/ Faculty of Medicine Universitas Airlangga, Surabaya, Indonesia (e-mail: heri-suroto@fk.unair.ac.id).
${ }^{5}$ Institute of Orthopaedics and Musculoskeletal Science, University College London, United Kingdom

J Reconstr Microsurg 2022;38:511-523.

\author{
Abstract \\ Keywords \\ - traumatic brachial \\ plexus injury \\ - brachial plexus \\ neuropathies \\ - epidemiologic studies \\ - developing countries \\ - nerve reconstruction \\ - reconstructive \\ surgery
}

Background Brachial plexus injuries (BPI) cause severe physical disability and major psycho-socioeconomic burden. Although various countries have reported BPI incidence, the data from Indonesia as the fourth most populated country in the world remains unknown. We aim to assess the distribution of traumatic BPI, patients' characteristics, and treatment modalities in Indonesia.

Methods A retrospective investigation was performed comprising $491 \mathrm{BPI}$ patients at a tertiary referral hospital in Indonesia from January 2003 to October 2019. Demographic and outcomes data were retrieved from medical records.

Results The average BPI patients' age was $27.3 \pm 11.6$ years old, with a male/female ratio of 4.6:1. Motorcycle accidents caused the majority (76.1\%) of all BPI cases. Concomitant injuries were present in $62.3 \%$ of patients, dominated by fractures (57.1\%) and brain injuries (25.4\%). BPI lesion type was classified into complete (C5$\mathrm{T} 1$, observed in $70 \%$ patients), upper (C5-C6, in 15\% patients), extended upper (C5-C7, in $14 \%$ patients), and lower type (C8-T1, in $1 \%$ patients). The average time to surgery was 16.8 months (range 1-120 months), with the majority (76.6\%) of the patients was operated on six months after the trauma. Free functional muscle transfer (FFMT) was the most common procedure performed (37\%). We also analyzed the functional outcomes (active range of motion (AROM) and muscle power), DASH (Disabilities of the Arm, Shoulder, and Hand) score, and VAS (Visual Analogue Scale) across four most frequent procedures involving nerve reconstruction (FFMT, nerve transfer, external neurolysis, and nerve grafting). We found that FFMT was significantly better than nerve transfer in terms of DASH score and VAS ( $p=0.000$ and $p=0.016$, respectively) in complete BPI (C5-T1). Moreover, we also found that nerve grafting resulted in a significantly better shoulder abduction AROM than nerve transfer and external published online

September 1, 2021
DOI https://doi.org/ $10.1055 / \mathrm{s}-0041-1735507$. ISSN 0743-684X.

\footnotetext{
(C) 2021. The Author(s).

This is an open access article published by Thieme under the terms of the Creative Commons Attribution-NonDerivative-NonCommercial-License, permitting copying and reproduction so long as the original work is given appropriate credit. Contents may not be used for commercial purposes, or adapted, remixed, transformed or built upon. (https://creativecommons.org/ licenses/by-nc-nd/4.0/)

Thieme Medical Publishers, Inc., 333 Seventh Avenue, 18th Floor, New York, NY 10001, USA
} 
neurolysis in extended upper BPI (C5-C7) ( $p=0.033$ and $p=0.033$, respectively). Interestingly, no significant differences were observed in other measurements.

Conclusion This study provides an overview of traumatic BPI patients in a single tertiary trauma center in Indonesia, expressing the profile of their characteristics and functional outcomes after surgical procedures.

Brachial plexus injury (BPI) is one of the most devastating injuries affecting the upper limb, leading to functional impairment, physical disability, socioeconomic burden, and psychological disorders that mostly affects young man in their productive age. ${ }^{1-5}$ A study from Kaiser et al. stated that the most common cause of BPI cases is trauma, mainly from motorcycle accidents (67\%). ${ }^{6}$ There were $112,771,136$ units of motorcycles registered in 2019 in Indonesia, making motorcycles the most common mode of transportation used (81.78\%) in the country, with annual increment of $6.2 \%{ }^{7}$ Between 2010 and 2019, the incidence of road traffic accidents in Indonesia has escalated by $75.09 \%$, reaching 116,411 accidents in 2019. ${ }^{7,8}$ The unpleasant trend observed during the last 10-year period puts motorcyclists in Indonesia as the most vulnerable group to suffer from road traffic accidents that can further lead to traumatic BPI.

A study from Narakas ${ }^{9}$ with a total of 1,068 patients obtained over 18 years formulated the "Law of The Seven Seventies," which stated: (1) $70 \%$ of BPI cases are caused by road traffic accidents; (2) 70\% of them are from two-wheeled accidents; (3) $70 \%$ of patients have associated multiple injuries; (4) $70 \%$ of patients have a supraclavicular lesion; (5) $70 \%$ of supraclavicular lesions have at least one root avulsion; (6) 70\% of root avulsions are in the $\mathrm{C} 7, \mathrm{C} 8$, or $\mathrm{T} 1 \mathrm{root}$; (7) $70 \%$ of patients with lower root avulsion will experience persisting pain. ${ }^{9}$ The "Law of the Seven Seventies" has been frequently quoted and used to compare the findings and outcomes at various centers. ${ }^{10}$ Several epidemiologic studies have been reported in various countries (China, ${ }^{3}$ India, ${ }^{10}$ USA, ${ }^{11}$ Taiwan, $^{12}$ and Thailand ${ }^{13}$ ). Despite its massive population (more than 268 million people in 2019), ${ }^{14}$ the incidence of traumatic BPI in Indonesia remains unknown.

Since the 2000s, the number of BPI patients referred to our center has increased due to the improvement in emergency management and the referral system development to our tertiary hospital. These improvements were inseparable from the role of national health insurance, BPJS (Balai Penyelanggara Jaminan Sosial), since 2014. From all over Indonesia, 491 traumatic BPI patients have been referred and surgically treated at Dr. Soetomo General Academic Hospital from January 2003 to October 2019. We believe this number is underestimated because many traumatic BPI patients have not been presented to the hospital due to common traditional shaman practices and transportation difficulties arising from challenging geographical nature of Indonesia.

The main purpose of this epidemiologic study was to assess the distribution and characteristics of traumatic BPI patients, their lesion types, treatment modalities, and outcomes in a large retrospective cohort of patients who underwent BPI surgery at our institution over a period of 16 years.

\section{Methods}

This retrospective study consists of 491 consecutive patients who underwent surgical treatment for traumatic BPI performed at Dr. Soetomo General Academic Hospital from January 2003 to October 2019. The Department of Orthopedics and Traumatology of Dr. Soetomo General Hospital in Surabaya is one of the three referral centers for patients with severe BPI from all over Indonesia. Information about age, sex, cause of injury, associated injuries, associated bone injury, patterns of injury, side of injury, time to surgery, operative procedure, and outcomes were retrieved from medical records of inpatients and outpatient clinics.

\section{Patient Selection}

Patients were referred from 27 out of 34 provinces in Indonesia. Written informed consent was obtained from the patient and approved by the local ethics committee (Clinical Research Unit of Dr. Soetomo Hospital) following the guidelines and regulations by ICH GCP. This study only included traumatic BPI patients in whom careful clinical examination and neurological evaluation gave an absolute indication for surgery, without any chances for spontaneous recovery. Patients who did not undergo surgical procedures were excluded from the study.

\section{Preoperative Planning}

Clinical and neurological assessments were performed on the patients who presented to the outpatient clinics. Those who came to the emergency room mostly suffered from multi-trauma injuries; thus, they were treated comprehensively by a multidisciplinary team to stabilize their general conditions. Stabilized patients underwent further neurophysiological assessment and cervical magnetic resonance imaging (MRI). Electromyography (EMG) and nerve conduction velocity (NCV) examinations were performed at least three weeks following trauma. Our BPI team also conducted monthly meetings with the patients and their families to discuss their clinical, neurophysiological, and radiological progress. We also informed the microsurgical reconstruction procedures that were planned, performed preoperative exercise for the donor nerve or muscle, and provided mental health support. The surgery priority scale was arranged according to the patients' time of arrival to the hospital. However, the patients who suffered from avulsion and subclavian artery injuries were prioritized.

\section{Microsurgical Treatment}

We performed microsurgical reconstruction involving nerve and muscle procedures. Primary nerve microsurgery was 
more favorable in early presentation ( $\leq 6$ months) and performed based on clinical, radiological, and neurophysiological findings. The choice of primary nerve microsurgery procedures performed was external neurolysis, nerve repair, nerve grafting, nerve transfer, and contralateral cervical 7 (CC7) transfer. The main reconstructive procedure was based on the principles of "no diagnosis, then no treatment" that it requires nerve lesion exploration to identify the healthy proximal and distal stumps to determine the appropriate treatment. ${ }^{15}$ External neurolysis was performed when the nerve root, trunk, cord, and terminal branch were found intact during the supra- and infraclavicular exploration, but fibrotic changes were present. Meanwhile, the nerve repair procedure was performed in a clean-cut injury.

Nerve grafting was performed when an intact proximal stump was found during exploration and was deemed eligible for grafting. After excision of the injured nerve, the C5 root was grafted to its terminal branch (suprascapular nerve) and the posterior division of upper trunk brachial plexus (which formed the axillary nerve) using an autograft donor nerve from the sural nerve. The C6 root was grafted to its terminal branch (musculocutaneous nerve) while the $\mathrm{C} 7$ was grafted to the radial nerve; both used the same donor. The $\mathrm{C} 8$ and $\mathrm{T} 1$ were left unexplored.

In case of no intact proximal stump was found during initial exploration, a nerve transfer may be indicated when a potential donor nerve with active motoric physiological functions was identified in preoperative (e.g., the phrenic nerve was assessed using clinical and radiologic findings) and intraoperative (using electrical stimulation) assessments. The donor nerve should have low donor morbidity after the transfer. Common donor nerve sites were phrenic nerve $(\mathrm{Ph})$, spinal accessory nerve/CN XI (accessed by a supraclavicular approach), and the intercostal nerve (ICN).

Intraoperative motoric nerve verification is an essential part of the nerve transfer procedure. Injured recipient nerves should be identified and assessed by electrical stimulation to avoid the cutting of recovering nerves and prevent donor nerve dissection. The donor nerve was dissected and evaluated for muscle contractility degree with electrical stimulation. The certainty of a tense-free nerve transfer without postural compensation can be done by freeing both proximal recipient nerve and distal donor nerve as far as possible. When considering the reconstruction of brachial plexus nerve injury, the available donor nerve and priority of function to be achieved for recovery must be identified. The highest priority is elbow flexion, followed by shoulder abduction, shoulder stability, and wrist extension.

The muscle procedure was mostly done by single free functional muscle transfer (FFMT). Pre-operative chest X-ray evaluation was performed to assess the diaphragm level. Symmetrical diaphragm level suggests a healthy phrenic nerve, which is the primary donor nerve choice for the FFMT procedure. After the phrenic nerve was identified during surgical exploration, its eligibility as a donor nerve was reevaluated using a nerve stimulator. Next, an infraclavicular approach was performed to find the thoracoacromial artery and cephalic vein as the primary sources of revascu- larization. As for the muscle transfer, the gracilis muscle was preferred because of its proximally located neurovascular pedicle (allowing fast reinnervation) and its long tendon, which could be secured to the distal muscles for wrist and fingers stabilization.

The gracilis muscle harvest started with performing three separate incisions: at the musculotendinous level, insertion site, and the proximal level to reach the origin site, motoric nerve branch, and the pedicle. To maximize the tendon length, a complete-length gracilis muscle $( \pm 44 \mathrm{~cm})$ along with its tendon $( \pm 6 \mathrm{~cm})$ was used, which was then transferred to the clavicle and secured to the extensor carpi radialis brevis (ECRB) tendon for wrist extension. The free gracillis muscle origin was attached to the middle third of the clavicle by suturing it to the bone. Its distal part, which was attached to the ECRB, was meant for restoring elbow flexion and wrist extension, considering tendon tension at the distal attachment. The free gracilis muscle was vascularized by the small-diameter thoracoacromial artery $(1.0$ to $2.5 \mathrm{~mm}$ ). Once the end-to-end anastomosis was completed, we simultaneously evaluated the artery patency and venous backflow to the cephalic vein. The free vascularized gracilis was reinnervated by the phrenic nerve. An additional nerve transfer of the spinal accessory nerve to the suprascapular nerve to reconstruct shoulder abduction and external rotation was also performed. Before the skin closure, the patency of the anastomosed vessels and the repaired nerve was reevaluated. However, a skin paddle was not routinely applied.

\section{Outcome Assessment}

We assessed and recorded the following outcomes: DASH (Disabilities of the Arm, Shoulder, and Hand) score, shoulder abduction active range of motion (AROM), shoulder abduction MRC (Medical Research Council), elbow flexion AROM, elbow flexion MRC, and VAS (Visual Analogue Scale) in the last follow-up visit.

Disabilities of the arm, shoulder, and head (DASH) score is a widely accepted scoring system to evaluate upper extremity musculoskeletal conditions. DASH score is a patient-reported outcome measure (PROM) questionnaire comprising 30 items to evaluate the entire upper extremity's symptoms and functions. Each item consists of five levels of answers ( $5=$ extreme difficulty (unable to do)/ symptoms, $4=$ severe difficulty/symptoms, $3=$ moderate difficulty/symptoms, $2=$ mild difficulty/symptoms, and $1=$ no difficulty/symptoms). A total score is calculated, with a range of 0 (no disability) to 100 (most severe disability). Lower DASH scores indicate better outcomes (fewer disabilities). ${ }^{16,17}$

Senior orthopedic surgeons and residents assessed the shoulder abduction and elbow flexion AROM as well as muscle power tests. Active range of motion (AROM) of the shoulder abduction and elbow flexion was measured using a goniometer and expressed in degrees, whereas muscle power was evaluated using MRC (Medical Research Council) grading system. MRC is the most commonly adopted muscle power grading system for manual muscle testing (MMT) worldwide. Despite the old age, 


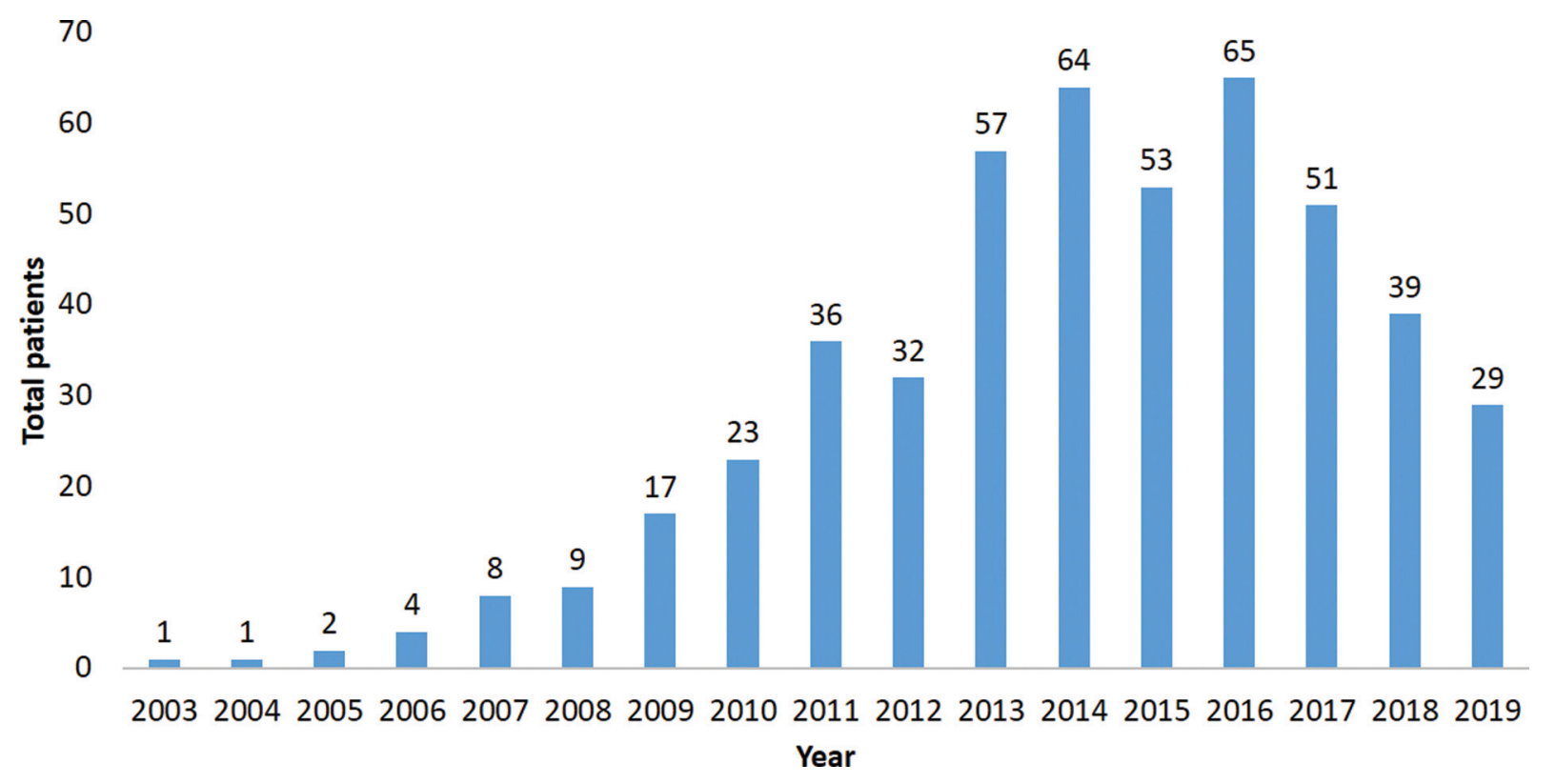

Fig. 1 Total BPI patients in the study period.

its reliability and validity remain relevant up to this day. The MRC scale comprised six levels of motor power evaluation, ranging from 0 to $5(0=$ no palpable/observable muscle contraction, $1=$ trace contraction/flickers, 2 = active movement with gravity eliminated, 3 = active movement against gravity but not resistance, 4 = active movement against gravity and resistance, $5=$ active movement with maximal resistance/normal muscle power). A higher score reflects a better functional motor power outcome. $^{18,19}$

Moreover, the pain was evaluated using visual analogue scales (VAS). Patients were asked to describe their level of pain on a scale of 0 to 10 ( 0 indicating no pain while 10 indicating the worst, unbearable pain). The lower scores reflect a better pain outcome. ${ }^{20,21}$

\section{Statistical Analysis}

Categorical variables were presented as frequencies and percentages (\%), while continuous variables were presented as means with standard deviations. Normality was tested using Kolmogorov-Smirnov tests. Normally distributed data were analyzed using one-way ANOVA tests, while abnormally distributed data were analyzed using Kruskal-Wallis tests to compare the means among the groups. Post-hoc tests were performed to identify which groups yielded significant differences. All of our data analyses were performed using SPSS 26.

\section{Results}

\section{Description of Patient Characteristics}

A total of 491 patients were assessed over a period of 16 years (average follow-up time $66.78 \pm 35.39$ months). The number of BPI cases started to increase from 2003, with the highest number of patients in 2014 and 2016, followed by a reduction of cases since in 2017 (-Fig. 1). The cases of traumatic BPI were widespread in Indonesia from the westernmost in
Aceh to the easternmost in Papua (-Fig. 2), with most cases came from East Java (59.47\%). The population consisted of 403 males and 88 females, with a male/female ratio of $4.6: 1$. The cohort's average age was $27.3 \pm 11.6$ years old ( $\mathbf{- F i g . ~} \mathbf{3}$ ).

\section{Description of Injury Types and Treatments}

Among BPI causes (-Table 1), the majority of injuries were caused by road traffic accidents (78.3\%), with motorcycle accidents contributed the most (76.1\%). In comparison, car accidents only caused a small portion (2.2\%) of traumatic BPI. Other causes of BPI (10.2\%) include: hit by a rifle, cut by a knife, hit and trapped by a broken wall, and others.

Of all BPI cases, 284 patients (57.8\%) had a right-sided injury, and 207 patients (42.2\%) had a left-sided injury. Concomitant (associated) injuries were present in $62.3 \%$ of patients, consisting of fractures (57.1\%), brain injuries (25.4\%), dislocation and sprain (8.4\%), chest injuries (3.9\%), and abdominal visceral injuries (1.3\%) (-Table 2). The most common fracture was clavicle fractures, observed in $25.7 \%$ of patients, followed by lower extremity (20.5\%) and humeral fractures (19.4\%) (-Table 2).

Only 115 patients $(23.4 \%)$ received surgical treatment within six months following trauma. The time to surgery was delayed (6-12 months) in 76 patients (15.5\%) and late (more than 12 months) in 300 patients (61.1\%) (-Fig. 4). The average time to surgery was 16.8 months (range 1 to 120 months). Late BPI was indicated for surgery if pain altered the quality of life significantly. Patients presenting with late BPI mostly came from outside of Java, and some of them suffered from multi-trauma injuries.

Moreover, the lesion type of BPI varied widely. Most of the cases had complete C5-T1 BPI (70\%), followed by upper C5-C6 (15\%) and extended upper C5-C7 BPI (14\%) type. In contrast, the fewest type of BPI was lower (C8-T1) type (1\%) (-Fig. 5). Among the complete BPI, $43 \%$ of them were fully 


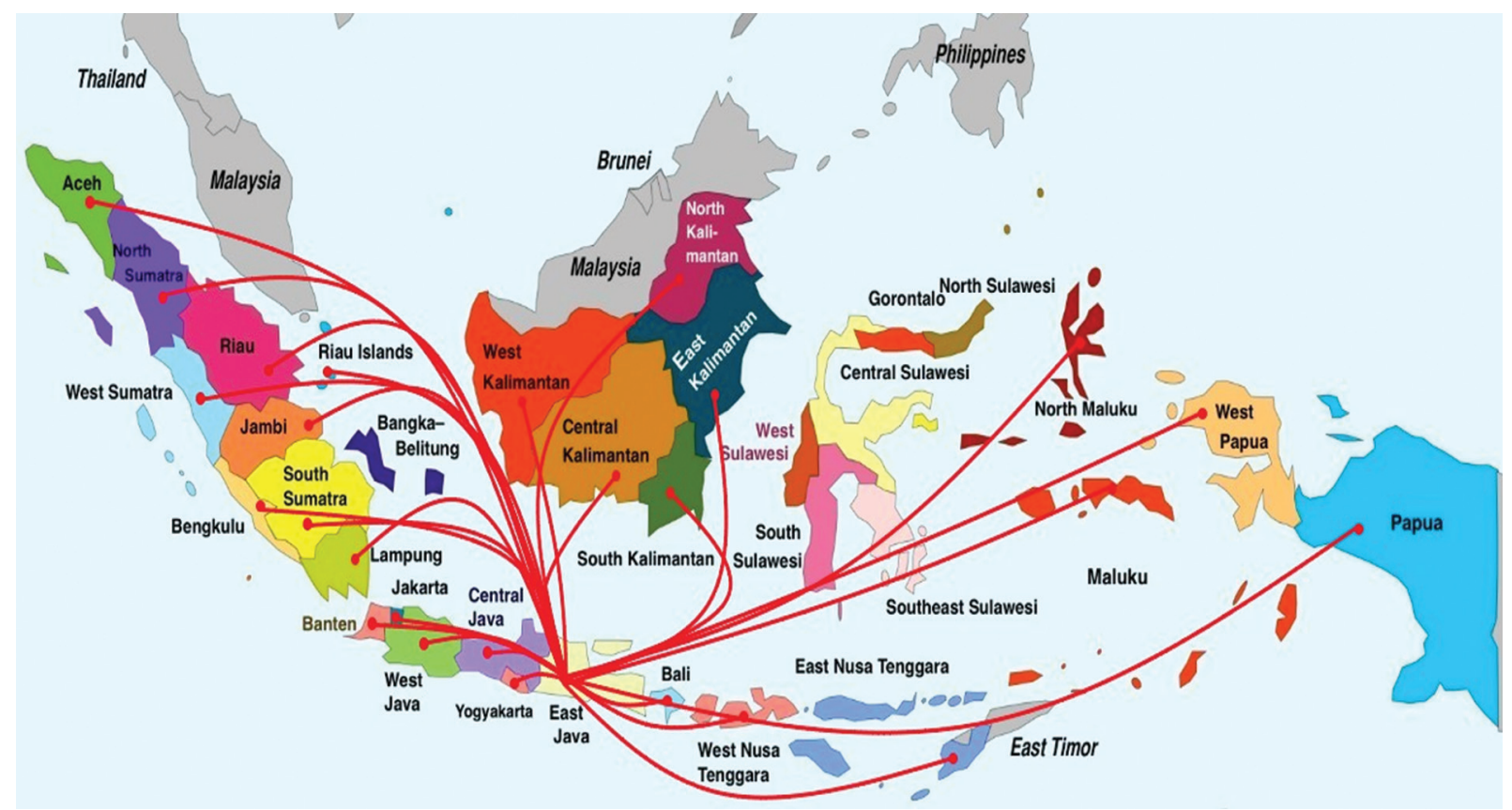

Fig. 2 The distribution of BPI patients in Indonesia.

200
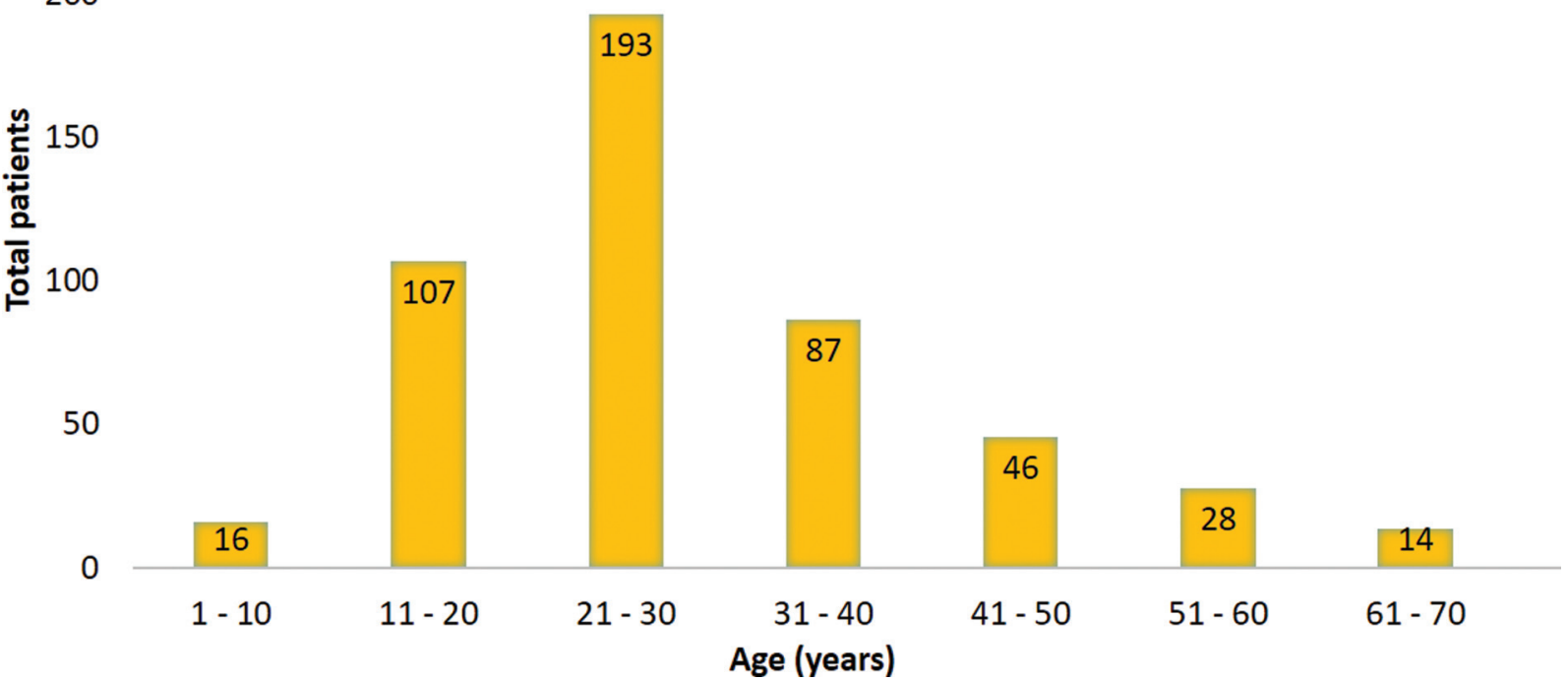

Fig. 3 Age distribution.

postganglionic (including supra- and infraclavicular lesions), while $27 \%$ of them had a preganglionic lesion of the plexus roots. Upper avulsion preganglionic BPI was suspected when radiological findings showed an asymmetrical diaphragm, while lower avulsion of preganglionic BPI was suspected when Horner syndrome was found. Preganglionic BPI could also be evident during surgical exploration.

The surgical techniques that we used also varied (-Table 3). Single FFMT was the most common surgical procedure performed (35\%), followed by nerve transfer (29\%) and external neurolysis (16\%). The choice of treatment strongly depended on the time of presentation to the hospital after the accident, type of lesion, and BPI severity.

\section{Analysis of Outcomes}

We assessed and recorded DASH score, shoulder abduction AROM, shoulder abduction MRC, elbow flexion AROM, elbow flexion MRC, and VAS during the last follow-up visit. We compared the four most commonly performed procedures relating to nerve reconstruction (nerve transfer, nerve grafting, external neurolysis, and FFMT). However, several patients were lost to follow-up due to sociogeographical 
Table 1 Cause of injury in BPI

\begin{tabular}{|l|l|l|}
\hline Cause of Injury & $\begin{array}{l}\text { Number of } \\
\text { patients }\end{array}$ & Percentage \\
\hline Motorcycle accidents & & \\
\hline Single motor injury & 165 & $33.6 \%$ \\
\hline Motorcycle vs motorcycle & 94 & $19.1 \%$ \\
\hline Motorcycle vs car & 115 & $23.4 \%$ \\
\hline Car Accidents & 11 & $2.2 \%$ \\
\hline Falls from height & 28 & $5.7 \%$ \\
\hline Occupational injury & 14 & $2.9 \%$ \\
Obstetric trauma & 14 & $2.9 \%$ \\
\hline Others & 50 & $10.2 \%$ \\
\hline TOTAL & 491 & $100.0 \%$ \\
\hline
\end{tabular}

discrepancies, resulting in only 315 patients included in the outcome analysis. The number of patients for each procedure that were included in the outcomes analysis according to their BPI lesion type is displayed in - Table 4.

Then, we performed non-parametric Kruskal-Wallis tests to compare the outcomes (-Table 5 ). We found significant differences in DASH and VAS score in complete BPI (C5-T1) and shoulder abduction AROM in extended upper BPI (C5C7). When we performed post-hoc tests ( - Table 6 ), we found that FFMT significantly lowered DASH score compared with nerve transfer in complete BPI (C5-T1) (31.97 \pm 50.20 versus $46.39 \pm 22.47, p=0.000$ ). Moreover, FFMT also significantly reduced pain compared with nerve transfer $(2.99 \pm 1.70$ versus $3.64 \pm 1.67, p=0.016$ ). These findings imply that FFMT leads to better outcomes (fewer disabilities, less pain) than nerve transfer in complete BPI (C5-T1). Also, we identified that nerve grafting significantly outperformed nerve transfer and external neurolysis to restore shoulder AROM $(123.33 \pm 35.12$ versus $57.63 \pm 31.46(p=0.033)$ and $123.33 \pm 35.12$ versus $42.50 \pm 54.39(p=0.033)$, respectively) in C5-C7 lesion. However, this result must be interpreted with caution as the patient numbers for this comparison were small and varied quite unequally between the groups.

\section{Discussion}

\section{Prevalence and Patient Characteristics}

This study of 491 BPI cases is a reflection of the current situation in our institution. However, this number may not have fully reflected the actual prevalence of BPI in Indonesia, as the microsurgery center in Indonesia is very limited; thus, many patients may have been underreported. The numbers of BPI cases were increasing initially, reaching its peak in 2014-2016. Dr. Soetomo General hospital was the first tertiary referral center capable of operating BPI cases in Indonesia, equipped with a comprehensive BPI team consisting of microsurgery orthopedic surgeons and rehabilitation medicine physicians. Currently, one BPI patient per week is operated on at our tertiary center in Surabaya. The patient numbers decline observed since 2017 was due to the
Table 2 Associated injuries of traumatic BPI

\begin{tabular}{|c|c|c|}
\hline Associated injuries & $\begin{array}{l}\text { Number of } \\
\text { cases }\end{array}$ & Percentage \\
\hline Brain Injury & 78 & $25.4 \%$ \\
\hline Minor & 12 & $15.3 \%$ \\
\hline Moderate & 42 & $53.8 \%$ \\
\hline Severe & 24 & $30.7 \%$ \\
\hline Rib Fractures & 10 & $3.2 \%$ \\
\hline $\begin{array}{l}\text { Flail chest, lung contusion, } \\
\text { hemopneumothorax }\end{array}$ & 12 & $3.9 \%$ \\
\hline Abdominal visceral injury & 4 & $1.3 \%$ \\
\hline Subclavian artery injury & 1 & $0.3 \%$ \\
\hline Fractures & 175 & $57.1 \%$ \\
\hline Clavicula & 45 & $25.7 \%$ \\
\hline Scapula & 11 & $6.2 \%$ \\
\hline Humerus & 34 & $19.4 \%$ \\
\hline Radius & 28 & $16 \%$ \\
\hline Ulna & 21 & $12 \%$ \\
\hline Lower extremity & 36 & $20.5 \%$ \\
\hline Dislocation & 20 & $6.5 \%$ \\
\hline Shoulder & 13 & $65 \%$ \\
\hline Elbow & 7 & $35 \%$ \\
\hline Shoulder sprain & 6 & $1.9 \%$ \\
\hline
\end{tabular}

development of another tertiary trauma center in Indonesia. However, the decrease in surgery performed did not necessarily reflect the reduction in new BPI cases; because in addition to being distributed in three tertiary hospital centers, the concomitant injuries accompanying BPI also required more urgent actions. - Table 2 shows a high percentage of fractures (57\%) and head injuries (25\%), whose treatments and rehabilitation will be prioritized. Thus, the patients and their families often preferred to put off microsurgery for nerve and muscle reconstruction. In the end, the patients came with late presentation (time to surgery was more than six months in $76.6 \%$ of patients) to undergo nerve and muscle reconstruction surgery.

This study shows that BPI cases occurred mostly in men who were in their productive age (21 to 30 years). Our result is in line with several previous studies, which also reported a high incidence in young male. ${ }^{2,3,10,22}$ The high incident rate in this age group (21 to 30 years old) was possibly due to many subjects using motorcycles as their primary vehicles to commute to work. The second highest incidence was observed in the adolescents (11 to 20 years old), indicating there might be a lack of supervision and proper education comprehension regarding driving safety. In 2013, the Headquarter State Police of the Republic Indonesia Traffic Corps reported 56,455 cases of motorcycle accidents among people in employment; 56,001 motorcycle accidents were caused by drivers without a valid driving license, and 4,717 cases of 
350

300

250

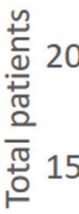

100

50

0

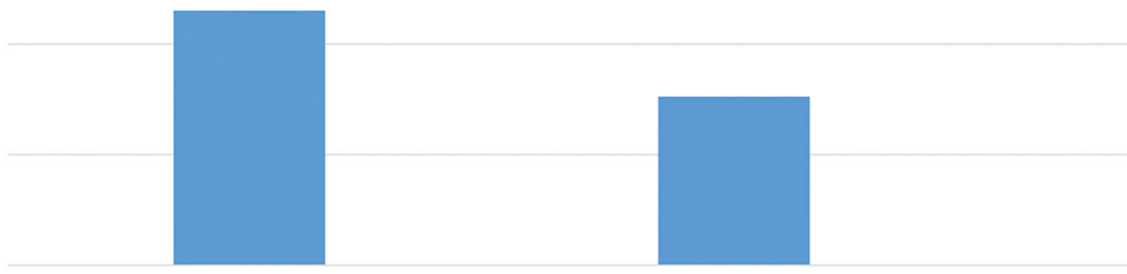

$<6$ months

Fig. 4 Time to surgery.

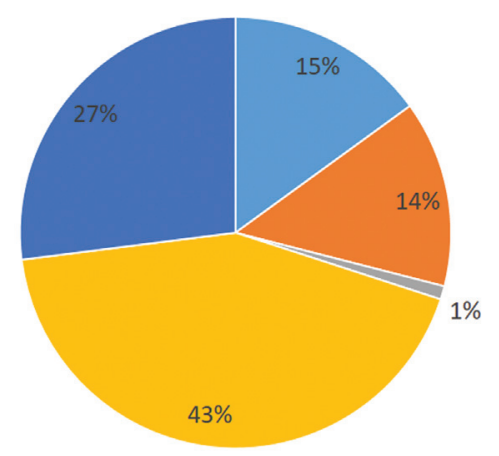

$\begin{array}{ll}=\mathrm{C} 5-\mathrm{C} 6(\text { upper BPI) } & =\mathrm{C} 5-\mathrm{C} 7 \text { (extended upper BPI) } \\ =\mathrm{C} 8-\mathrm{T} 1 \text { (lower BPI) } & =\mathrm{C} 5-\mathrm{T} 1 \text { (Complete BPI) postganglionic } \\ =\mathrm{C} 5-\mathrm{T} 1 \text { (complete BPI) preganglionic } & \end{array}$

Fig. 5 The distribution of paralysis.

motorcycle accidents were due to traffic violations. ${ }^{23}$ Furthermore, although it only accounts for a small proportion (3.26\%), the BPI affecting children (aged 1-10 years old) also requires special attention as it is often associated with root avulsions and no pain. However, satisfactory long-term outcomes were reported when appropriately managed. ${ }^{24}$

\section{Injury Types}

Several studies from developing countries are similar to ours and are following two points from the "Law of the Seven Seventies," stating that $70 \%$ of BPI cases were caused by traffic accidents, of which $70 \%$ were two-wheeled accidents. $3,9,13,25-27$ In our study, 78.3\% of BPI cases were caused by road traffic accidents. In contrast, studies from developed countries reported less than $70 \%$ of cases were caused by motorcycle accidents. ${ }^{22,28}$ The distinction of these results reflects that two-wheeled vehicles are a more common cause
Table 3 Operative procedures performed

\begin{tabular}{|l|l|l|}
\hline Surgery & No. of patients & Percentage (\%) \\
\hline Single FFMT & 172 & $35.03 \%$ \\
\hline Nerve Transfer & 144 & $29.32 \%$ \\
\hline External Neurolysis & 80 & $16.29 \%$ \\
\hline Flexorplasty & 34 & $6.92 \%$ \\
\hline Nerve Grafting & 32 & $6.51 \%$ \\
\hline Double FFMT & 10 & $2.03 \%$ \\
\hline Trapeziusplasty & 10 & $2.03 \%$ \\
\hline Nerve Repair & 7 & $1.42 \%$ \\
\hline C7 Contralateral & 2 & $0.45 \%$ \\
\hline TOTAL & 491 & $100.0 \%$ \\
\hline
\end{tabular}

of BPI in developing countries. Moreover, Leonard et al. also reported that the number of blunt traumatic brachial plexus injuries (BTBPIs) involving unshielded vehicles was significantly higher than those involving a shielded vehicle, especially in rural regions, as unshielded vehicles gave less protection to the drivers and passengers. ${ }^{29}$ In relation to the mode of injury due to "high speed" motorized accident, Rhee et al. found that all patients had associated injuries in addition to their spinal cord injury and brachial plexus injury. The most common associated injuries were to the head or face, loss of consciousness, and spine fractures (especially cervical spine fractures). ${ }^{30}$

Our study found that $62.3 \%$ of cases had associated multiple injuries, which is less than the $70 \%$ stated by Narakas. ${ }^{9}$ In these patients, $57.1 \%$ of them suffered from fractures, with clavicle fractures as the most common associated injury. Similar results were also reported in other 
Table 4 The number of patients analyzed based on lesion types and procedures

\begin{tabular}{|l|l|l|l|l|l|}
\hline $\begin{array}{l}\text { BPI lesion } \\
\text { type }\end{array}$ & $\begin{array}{l}\text { Nerve } \\
\text { transfer }\end{array}$ & $\begin{array}{l}\text { Nerve } \\
\text { grafting }\end{array}$ & $\begin{array}{l}\text { External } \\
\text { neurolysis }\end{array}$ & FFMT & Total \\
\hline C5-C6 & 25 & 3 & 12 & 8 & 48 \\
\hline C5-C7 & 19 & 3 & 4 & 7 & 33 \\
\hline C8-T1 & 1 & 0 & 0 & 4 & 5 \\
\hline C5-T1 & 59 & 12 & 18 & 140 & 229 \\
\hline Total & 104 & 18 & 34 & 159 & 315 \\
\hline
\end{tabular}

studies. ${ }^{13,28,31}$ Moreover, fractures and ligamentous injuries affecting the shoulder girdle region were also frequently found (22.2\%). Midha reported that more than $20 \%$ of patients had either shoulder dislocation or sprain. ${ }^{22}$ These shoulder girdle injuries were crucial markers for severe plexus injury. When the supraclavicular plexus was injured along with a humeral fracture and shoulder dislocation, the injury was almost always severe. Subclavian artery injury occurred in one patient in our cohort and was also associated with severe supraclavicular damage. ${ }^{6}$ Another common associated multiple injuries found were brain injuries, rib fractures, flail chest, hemopneumothorax, lung contusion, abdominal visceral injury, and subclavian artery injury, which were consistent with previous studies. ${ }^{2,3,30,32}$

In our cohort, $70 \%$ of patients had complete BPI (C5-T1), which typically had the worst prognosis, followed by the upper and lower lesion. Our result is similar to several studies. ${ }^{6,33,34}$ A meta-analysis study by Kaiser et al. also demonstrated that the typical patient suffering from severe BPI with closed supraclavicular injury mostly caused complete BPI and less commonly caused an upper plexus palsy. ${ }^{6}$

\section{Time to Surgery}

It is generally accepted that the period between the time of injury and surgery is crucial. Rapid intervention increases the ability to restore function, reduce chronic pain, and allow patients to return to their daily activities immediately. ${ }^{3} \mathrm{~A}$ recent cross-sectional study conducted by Adyaksa and Suroto found that the time to surgery affected the apoptotic level occurred at the proximal stump of the brachial plexus motorneuron. The expression of pro-apoptotic markers

Table 5 Comparison of functional outcomes among four procedures

\begin{tabular}{|c|c|c|c|c|c|c|}
\hline Outcome & Pathology level & Nerve transfer & Nerve grafting & External neurolysis & FFMT & $p$ Value \\
\hline \multirow[t]{4}{*}{ DASH score } & C5-C6 & $32.56 \pm 17.45$ & $27.33 \pm 12.81$ & $26.68 \pm 15.13$ & $40.22 \pm 27.77$ & 0.677 \\
\hline & C5-C7 & $40.17 \pm 17.05$ & $49.60 \pm 34.94$ & $35.98 \pm 23.87$ & $26.76 \pm 18.98$ & 0.357 \\
\hline & C8-T1 & $\mathrm{N} / \mathrm{A}$ & $\mathrm{N} / \mathrm{A}$ & $\mathrm{N} / \mathrm{A}$ & $27.57 \pm 24.24$ & $\mathrm{~N} / \mathrm{A}$ \\
\hline & C5-T1 & $46.39 \pm 22.47$ & $41.75 \pm 26.11$ & $34.59 \pm 18.42$ & $31.97 \pm 50.20$ & $0.000^{*}$ \\
\hline \multirow{4}{*}{$\begin{array}{l}\text { Shoulder abduction } \\
\text { AROM }\end{array}$} & C5-C6 & $82.80 \pm 47.37$ & $86.67 \pm 5.77$ & $107.92 \pm 60.13$ & $53.75 \pm 29.00$ & 0.119 \\
\hline & $C 5-C 7^{a}$ & $57.63 \pm 31.46$ & $123.33 \pm 35.12$ & $42.50 \pm 54.39$ & $75.71 \pm 39.10$ & $0.027^{*}$ \\
\hline & C8-T1 & $\mathrm{N} / \mathrm{A}$ & $\mathrm{N} / \mathrm{A}$ & $\mathrm{N} / \mathrm{A}$ & $161.25 \pm 19.31$ & $\mathrm{~N} / \mathrm{A}$ \\
\hline & C5-T1 & $56.86 \pm 43.76$ & $73.33 \pm 60.35$ & $88.33 \pm 58.06$ & $58.32 \pm 37.23$ & 0.110 \\
\hline \multirow{4}{*}{$\begin{array}{l}\text { Shoulder abduction } \\
\text { MRC }\end{array}$} & C5-C6 & $3.12 \pm 0.89$ & $3.33 \pm 0.58$ & $3.58 \pm 1.17$ & $3.13 \pm 0.99$ & 0.621 \\
\hline & $\mathrm{C} 5-\mathrm{C} 7$ & $2.53 \pm 0.84$ & $3.33 \pm 1.16$ & $2.00 \pm 1.41$ & $2.86 \pm 0.70$ & 0.288 \\
\hline & C8-T1 & $\mathrm{N} / \mathrm{A}$ & $\mathrm{N} / \mathrm{A}$ & $\mathrm{N} / \mathrm{A}$ & $4.50 \pm 0.58$ & $\mathrm{~N} / \mathrm{A}$ \\
\hline & C5-T1 & $2.61 \pm 1.13$ & $2.67 \pm 1.44$ & $3.33 \pm 1.24$ & $2.80 \pm 1.09$ & 0.149 \\
\hline \multirow[t]{4}{*}{ Elbow flexion AROM } & $\mathrm{C} 5-\mathrm{C} 6$ & $103.00 \pm 43.97$ & $113.33 \pm 46.46$ & $121.67 \pm 45.49$ & $108.13 \pm 41.74$ & 0.348 \\
\hline & C5-C7 & $103.68 \pm 39.22$ & $128.33 \pm 33.29$ & $67.50 \pm 59.09$ & $100.00 \pm 32.15$ & 0.324 \\
\hline & C8-T1 & N/A & $\mathrm{N} / \mathrm{A}$ & $\mathrm{N} / \mathrm{A}$ & $146.25 \pm 12.50$ & $\mathrm{~N} / \mathrm{A}$ \\
\hline & C5-T1 & $87.54 \pm 43.30$ & $85.42 \pm 61.77$ & $104.72 \pm 45.42$ & $81.96 \pm 43.39$ & 0.115 \\
\hline \multirow[t]{4}{*}{ Elbow flexion MRC } & C5-C6 & $3.36 \pm 0.86$ & $3.67 \pm 0.58$ & $3.92 \pm 0.90$ & $3.50 \pm 0.93$ & 0.346 \\
\hline & C5-C7 & $3.37 \pm 0.76$ & $4.00 \pm 0.00$ & $2.75 \pm 1.26$ & $3.43 \pm 0.54$ & 0.264 \\
\hline & C8-T1 & $\mathrm{N} / \mathrm{A}$ & $\mathrm{N} / \mathrm{A}$ & $\mathrm{N} / \mathrm{A}$ & $4.50 \pm 0.58$ & $\mathrm{~N} / \mathrm{A}$ \\
\hline & C5-T1 & $3.08 \pm 1.15$ & $3.00 \pm 1.41$ & $3.39 \pm 1.24$ & $3.13 \pm 1.11$ & 0.677 \\
\hline \multirow[t]{4}{*}{ VAS } & C5-C6 & $2.48 \pm 1.74$ & $3.33 \pm 2.52$ & $2.08 \pm 1.68$ & $2.13 \pm 1.13$ & 0.743 \\
\hline & $\mathrm{C} 5-\mathrm{C} 7$ & $2.42 \pm 1.17$ & $2.00 \pm 1.00$ & $3.75 \pm 1.71$ & $2.43 \pm 1.13$ & 0.325 \\
\hline & C8-T1 & $\mathrm{N} / \mathrm{A}$ & $\mathrm{N} / \mathrm{A}$ & $N / A$ & $1.25 \pm 0.50$ & $\mathrm{~N} / \mathrm{A}$ \\
\hline & C5-T1 & $3.64 \pm 1.67$ & $3.75 \pm 1.60$ & $3.39 \pm 2.15$ & $2.99 \pm 1.70$ & $0.012^{*}$ \\
\hline
\end{tabular}

Abbreviation: N/A, Data not available.

*Statistically significant $(p<0.05)$.

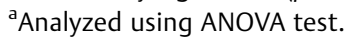


Table 6 Post-hoc tests

\begin{tabular}{|l|l|l|l|}
\hline Procedure comparison & $\begin{array}{l}\text { Shoulder Abduction } \\
\text { AROM of extended } \\
\text { upper BPI (C5-C7) }\end{array}$ & $\begin{array}{l}\text { DASH score of } \\
\text { complete BPI } \\
\text { (C5-T1) }\end{array}$ & $\begin{array}{l}\text { VAS of complete } \\
\text { BPI (C5-T1) }\end{array}$ \\
\hline FFMT vs nerve transfer & 0.677 & $0.000^{*}$ & $0.016^{*}$ \\
\hline FFMT vs nerve grafting & 0.251 & 0.331 & 0.409 \\
\hline FFMT vs external neurolysis & 0.475 & 0.530 & 1.000 \\
\hline Nerve transfer vs nerve grafting & $0.033^{*}$ & 1.000 & 1.000 \\
\hline Nerve transfer vs external neurolysis & 0.873 & 0.815 & 1.000 \\
\hline Nerve grafting vs external neurolysis & $0.033^{*}$ & 1.000 & 1.000 \\
\hline
\end{tabular}

Note:

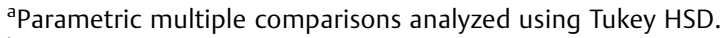

${ }^{b}$ Non-parametric pairwise comparisons; significance values have been adjusted by the Bonferroni correction for multiple tests.

*Statistically significant $(p<0.05)$.

(Caspase-3, Caspase-8, and Caspase-9) in the proximal stump biopsy of BPI patients who were operated on in late presentation (more than six months following trauma) was significantly higher than those who were operated on in early presentation (less than six months), suggesting the importance of performing nerve procedure surgery as soon as possible for a more desirable result. ${ }^{35}$ The average time to surgery in our study was 16.8 months, with the majority of the patients $(76.6 \%)$ had delayed or late surgery (more than six months). This may partly explain the insignificant outcomes found in our cohorts.

In comparison to several studies from developing countries, Indonesia has a bigger problem of late presentation of BPI to the hospital. ${ }^{2,10,25}$ Although the recommendation to undergo surgery within four to five months was reported in several developed countries, it is often not applicable in our patient population. ${ }^{33,36,37}$ The differences lie in Indonesia's economic, educational, and geographical conditions. Indonesia's socioeconomic and education system is centered on Java island; thus, there might be a stark discrepancy between the patients who came from outside Java and within Java. Moreover, Indonesia itself is an archipelago country of over 16,000 islands, whose geographical condition hampers patients' referral to a trauma center qualified to manage BPI cases. ${ }^{38}$ As an academic and tertiary hospital, it is our responsibility to build a center with microsurgical facilities in other cities in Indonesia and develop good communication with hospitals in the rural area so that the BPI cases can be managed better in the future. ${ }^{39}$ However, of course, this is not an easy task. Good collaboration is required from various parties and levels, starting from the family, community, regional to central hospitals, and stakeholders.

\section{Treatments and Outcomes}

In general, BPI management's surgical techniques vary from primary nerve procedures to secondary muscle and/or tendon procedures. Nerve procedures include exploration and external neurolysis, nerve repair, nerve grafting, nerve transfer, and contralateral C7 (CC7) nerve transfer. Muscle and/or tendon procedures include single FFMT, double FFMT, flexorplasty, and trapeziusplasty. Diverse nerve procedure preference exists in the literature. Dubuisson et al., Li et al., and Jain et al. recommended nerve transfer procedures, while Kandenwein et al. recommended nerve grafting instead. $3,10,28,36$ Nevertheless, Mackinnon observed a rapid increase of nerve transfer reports in the literature in the last three decades, shifting nerve graft and nerve repair aside. Nerve transfer was also suggested as a promising alternative technique in the future to address nerve injuries. $^{40}$ Moreover, Chuang recommended the traditional proximal over the emerging distal nerve transfer as it requires less cerebral adaptation and offers more accurate diagnosis, thus results in better outcomes. A combination of both techniques (with distal nerve transfer as an adjunct) is helpful, primarily when no adequate donor nerve available. ${ }^{15}$ Meanwhile, FFMT is a relatively rare performed procedure in the literature.

The decision of surgical intervention mostly depends on the BPI severity and the time to surgery. FFMT was the most commonly performed procedure in our cohort because many patients came with delayed presentation (more than six months after trauma). Moreover, $70 \%$ of cases were complete BPI, of which $38 \%$ were avulsion injuries. The other reason for performing FFMT was the limitation of motor nerve sources. Nerve transfer was performed when the time to surgery was less than nine months in postganglionic complete BPI cases, upper and extended upper BPI, and lower BPI.

Our outcomes (-Table 5 and $\mathbf{6}$ ) showed that the elbow flexion AROM and MRC, the shoulder abduction AROM and MRC were comparable among four procedures (nerve transfer, nerve grafting, external neurolysis, and FFMT) in all BPI pathology levels, except shoulder abduction AROM in extended upper BPI ( $\mathrm{C} 5-\mathrm{C} 7)$. This finding is surprising, as FFMT procedure is mostly performed in complete BPI patients with delayed presentation (more than 6 months), in whom satisfactory results are previously considered unlikely. The mean time to surgery of our cohort is 16.8 months, with $15.5 \%$ patients came with delayed presentation (6-12 months) and $61.1 \%$ with late presentation ( $>12$ months); thus, nerve procedures are no longer indicated, leaving FFMT as the best option. FFMT is generally a technically demanding 
procedure; nevertheless, our finding showed comparable results (AROM and MRC) to other nerve procedures despite FFMT patients' more complex characteristics.

A discussion that may be of interest to FFMT is the source of donor nerves. A systematic review comprising 312 FFMT procedures conducted by Oliver et al. found similar success rates (i.e., elbow flexion MRC $\geq 3$ ) between FFMTs innervated by spinal accessory and intercostal nerves $(65.4 \%$ and $64.1 \%$, respectively). ${ }^{41}$ Meanwhile, our present study found that $120 / 159$ patients included in the analysis achieved elbow flexion MRC $\geq 3$ (success rate $75.47 \%$ ) by utilizing the following donor nerve (sorted in descending order based on our preference): phrenic, spinal accessory, and intercostal nerves. However, we did not subdivide them based on donor nerve source as it is beyond the scope of this study.

The absence of muscle innervation (as seen in BPI) will lead to muscle atrophy through 3 stages, which can occur in years period, but it is a definite process, namely: rapid mass loss along with immediate voluntary function loss; sarcomeric organization loss; and infiltration of fibrous connective tissue and fat (muscle fiber degeneration). ${ }^{42}$ Moreover, the denervation and reinnervation period is inversely correlated with the muscle contraction recovery process, i.e., the longer denervation and reinnervation period, the weaker the muscle contraction is. In fact, motor endplates will experience critical damage that may lead to irreversible alteration of the denervated muscle in 12-18 months if sprouts from the repair site have not reached the muscle by that time. ${ }^{42,43}$ Thus, FFMT with gracilis muscle is often used as a salvage procedure in BPI (especially in delayed presentation or failed primary procedure) due to the following reasons: having functional similarities with arm and forearm muscles as well as microvascular supplies, low morbidity in donor site, possess a reliable and relatively long motor nerve. ${ }^{44,45}$ Successful revascularizations in FFMT will lead the gracilis muscle, a living muscle that requires a shorter reinnervation period, to regain the elbow and shoulder function. Therefore, FFMT could result in satisfactory outcomes, which are comparable to the other nerve procedures.

We also found that nerve grafting in extended upper BPI (C5-C7) showed a significantly better shoulder abduction AROM than nerve transfer and external neurolysis $(p=0.033)$. Previous studies comparing the outcome of nerve grafting and nerve transfer in BPI also found that nerve transfer showed a better outcome. ${ }^{46-48}$ In the early presentation (less than 6 months), BPI with stretch injury or without root avulsion, nerve grafting is preferred. Likewise, nerve grafting is a traditional reconstruction method of postganglionic BPI. ${ }^{49}$ Nerve repair using this method could reduce the tension within the nerve so that the reinnervation process could occur and even be accelerated. ${ }^{49,50}$ However, nerve grafting has several disadvantages, namely: donor site morbidity, the difficulties in determining the suitable root for grafting, non-viable nerve stumps, a longer route between the regenerating axon and denervated motor endplates. ${ }^{46,48}$

Meanwhile, nerve transfer offers additional neurotization sources, suitable for BPI with root avulsion, facilitates regenerating axons closer to the denervated motor endplates (faster reinnervation), and no necessity for re-educating the muscle. Nevertheless, potential drawbacks include reduced function or co-contraction of the donor muscle. $^{47,49-51}$ In external neurolysis, as long as surviving axons are sufficient, releasing nerve conduction block will lead to reinnervation, improvement of axoplasmic transportation, and axon growth. ${ }^{52}$ The distinction in our result with other outcomes could be caused by the unequal number of patients across the groups; thus, the result may have been compromised. Nevertheless, BPI is a complicated condition whose outcomes could be affected by many factors such as injury mechanism, injury severity, pathology level, concomitant injuries, age, comorbid diseases, and physician experience. ${ }^{52}$ We should always consider these factors in planning nerve reconstruction to gain satisfactory outcomes.

Interestingly, an impressive phenomenon was observed in the DASH and VAS score, in which FFMT resulted in a more desirable outcome than nerve transfer in complete BPI (C5T1). Although the overall elbow and shoulder function (AROM and MRC) after FFMT was not significantly different from nerve transfer, the disability level and the pain outcome following nerve transfer were significantly worse than FFMT. A comparative study by Potter and Ferris found that primary gracilis FFMT reinnervated by the distal spinal accessory nerve (dSAN) resulted in better elbow flexion restoration than the ulnar nerve procedure. They observed that all patients who underwent dSAN reinnervated-gracilis FFMT procedures regained grade 4 elbow MRC. In contrast, the same achievement only occurred in less than $50 \%$ of patients who underwent nerve procedures. Thus, they concluded that FFMT was the most reliable reconstruction modality to restore elbow flexion in severe BPI. ${ }^{53}$

The 30-item DASH questionnaire includes 21 physical activity items, five symptom severity items, and four social function items. The significant DASH score difference between FFMT and nerve transfer procedure that we found may be due to the involvement of psychological factors present in chronic BPI patients (as most FFMT procedures were performed in delayed/late presentation). The DASH score was found to be reported significantly higher in patients with psychological complaints, ${ }^{54}$ with pain being the most crucial factor. ${ }^{55}$ The literature has also reported that $24.39 \%$ of BPI patients were diagnosed with major depression and 7.3\% with suicidal thoughts. ${ }^{5}$ Likewise, our finding also found a significant pain (VAS) difference, favoring FFMT compared with nerve transfer. Chronic pain has been associated with reduced quality of life, interfering with physical functioning, professional and private life, sleep, and mood. ${ }^{56}$ Thus, as the chronic BPI patients have been long psychosocially impaired, the FFMT surgery may probably contribute to improving their overall quality of life as well. However, we did not find any significant differences with the other two procedures and other pathology levels, which may be due to the small patient numbers.

\section{Limitations and Future Directions}

This study's limitation is we could not achieve hand prehension (grasping), especially in lower type and avulsion BPI, 
which involved C8 and T1 nerve root. Moreover, both CC7 transfer to the median nerve and FFMT with distal attachment to flexor pollicis and flexor digitorum profundus tendon still resulted in nonfunctioning hand. Another limitation is that our sample number differed non-equally across the groups, which might be a relatively unideal condition for statistical comparison. Not to mention the problem of patient follow-up and rehabilitation, which certainly plays a major role in restoring maximal functions of the upper limbs to carry out daily activities. Considering these issues, our results may have been affected due to the above factors. Future research should explore the correlation between the geographical condition and patient factors (socioeconomic level, rehabilitation compliance) to the outcomes. Nevertheless, amidst our limitations, we are still working to improve the quality of our services and provide the best support for our patients.

In May 2011, we formed the Indonesian Brachial Plexus Community (Komunitas Plexus Brachialis Indonesia) to facilitate our patients better. By using social media (WhatsApp and Facebook group), we maintain intense communication between patients, families, and care providers. Currently, there are 495 members of this community. Before the COVID-19 pandemic, a community gathering was held biannually; however, after the COVID-19 era, we held the events virtually. By having this community, communication in terms of case finding, preparation before surgery, implementation of postoperative rehabilitation programs can be done better. The constraints arising from geographical, time, and limited resources along with their consequences are also thoroughly elaborated to the patients and their families, as well as the healthcare providers from various hospital levels. Continuous system development, in-depth education, and training for district and sub-district healthcare providers must be implemented in the future to achieve maximal results. However, realizing the complexity of Indonesian patients' characteristics and geographical conditions, we believe our study still provides meaningful evidence about BPI's description in Indonesia along with its treatment modalities and outcomes.

\section{Conclusion}

This study provides an overview of BPI cases in one tertiary trauma center in Indonesia, reflecting the situation in this country. Due to the country's socioeconomic and geographical conditions, the high number of motorcycle accidents and delayed/late presentation to our tertiary center is undeniably challenging. Our current patient population demands high technical skills in secondary muscle and tendon procedures, as well as qualified rehabilitation support. A proper referral system and comprehensive multidisciplinary teamwork are necessary to provide the best care for BPI patients, which will also affect the patients' treatment and outcome.

\section{Ethical Approval}

Approval for this study was obtained from our institution's ethical clearance (Reference number: 1399/KEPK/VIII/2019).

\section{Author Contribution}

HS devised the project, the main conceptual ideas and proof outline. IA, AS, TCS, TP, BDV, and HM processed the experimental data, performed the analysis, and drafted the manuscript. All authors discussed the results and reviewed the manuscript.

\section{Data Availability}

The authors confirm that the data supporting the findings of this study are available within the article.

\section{Conflict of Interest}

The authors declare that they have no conflict of interest. Each author certifies that he or she has no commercial associations (e.g., consultancies, stock ownership, equity interest, patent/licensing arrangements, etc) that might pose a conflict of interest in connection with the submitted article

\section{Acknowledgments}

We would like to express our gratitude to the Orthopedic and Traumatology Department of Dr. Soetomo General Hospital (Surabaya, Indonesia) for supporting this study and Ms. Evlyn Santoso (administrative staff of Cell and Tissue Bank Dr. Soetomo General Hospital Surabaya) for her editing assistance.

\section{References}

1 Bonham C, Greaves I. Brachial plexus injuries. Trauma 2011;13 (04):353-363 Available at: https://journals.sagepub.com/doi/ $10.1177 / 1460408611405298$

2 Faglioni W Jr, Siqueira MG, Martins RS, Heise CO, Foroni L. The epidemiology of adult traumatic brachial plexus lesions in a large metropolis. Acta Neurochir (Wien) 2014;156(05):1025-1028. Doi: 10.1007/s00701-013-1948-X

3 Li G-Y, Xue M-Q, Wang J-W, Zeng X-Y, Qin J, Sha K. Traumatic brachial plexus injury: a study of 510 surgical cases from multicenter services in Guangxi, China. Acta Neurochir (Wien) 2019; 161(05):899-906. Doi: 10.1007/s00701-019-03871-y

4 Kaiser R, Mencl L, Haninec P. Injuries associated with serious brachial plexus involvement in polytrauma among patients requiring surgical repair. Injury 2014;45(01):223-226. Doi: 10.1016/j.injury.2012.05.013

5 Suroto H, Putra RA, Karimah A. Relationship between disability and pain to post-traumatic stress disorder, depression, and anxiety in patient with postoperative brachial plexus injury (BPI). BrJ Neurosurg 2021;35(03):254-258. Doi: 10.1080/02688697.2020.1784846

6 Kaiser R, Waldauf P, Ullas G, Krajcová A Epidemiology, etiology, and types of severe adult brachial plexus injuries requiring surgical repair: systematic review and meta-analysis. Neurosurgical Review 2020/04/01 2020;43(02):443-452. Doi: 10.1007/ s10143-018-1009-2

7 BPS. Statistics SoT, ed. Land transportation statistics 2019. BPSStatistics Indonesia. 2020 Accessed Feb 9, 2021. https://www.bps. go.id/publication/2020/11/20/ddce434c92536777bf07605d/statistik-transportasi-darat-2019.html

8 BPS. Statistics SoT, ed. Land transportation statistics 2014. BPSStatistics Indonesia. 2015 Accessed Feb 9, 2021. https://www.bps. go.id/publication/2015/11/10/dc32fd4a803f4fc29e24df4b/statistiktransportasi-darat-2014.html

9 Narakas AO. The treatment of brachial plexus injuries. Int Orthop 1985;9(01):29-36. Doi: 10.1007/BF00267034 
10 Jain DKA, Bhardwaj P, Venkataramani H, Sabapathy SR. An epidemiological study of traumatic brachial plexus injury patients treated at an Indian centre. Indian J Plast Surg 2012;45(03): 498-503. Doi: 10.4103/0970-0358.105960

11 Dy CJ, Peacock K, Olsen MA, Ray WZ, Brogan DM. Incidence of Surgically Treated Brachial Plexus Injury in Privately Insured Adults Under 65 Years of Age in the USA. HSS J 2020;16 (Suppl 2):339-343. Doi: 10.1007/s11420-019-09741-8

12 Chuang DC. Adult brachial plexus reconstruction with the level of injury: review and personal experience. Plast Reconstr Surg 2009; 124(6, Suppl)e359-e369. Doi: 10.1097/PRS.0b013e3181bcf16c

13 Songcharoen P. Brachial plexus injury in Thailand: a report of 520 cases. Microsurgery 1995;16(01):35-39. Doi: 10.1002/micr. 1920160110

14 BPS. Publication SoSCa, ed. Statistical yearbook of Indonesia 2020. BPS-Statistics Indonesia. 2020 Accessed Feb 9, 2021. https:// www.bps.go.id/publication/2020/04/29/ e9011b3155d45d70823c141f/statistik-indonesia-2020.html

15 Chuang DC. Distal Nerve Transfers: A Perspective on the Future of Reconstructive Microsurgery. J Reconstr Microsurg 2018;34(09): 669-671. Doi: 10.1055/s-0038-1656719

16 Beaton DE, Katz JN, Fossel AH, Wright JG, Tarasuk V, Bombardier C. Measuring the whole or the parts? Validity, reliability, and responsiveness of the Disabilities of the Arm, Shoulder and Hand outcome measure in different regions of the upper extremity. J Hand Ther 2001;14(02):128-146. Doi: 10.1016/S0894-1130 (01)80043-0

17 Hudak PL, Amadio PC, Bombardier CThe Upper Extremity Collaborative Group (UECG) Development of an upper extremity outcome measure: the DASH (disabilities of the arm, shoulder and hand) [corrected]. Am J Ind Med 1996;29(06):602-608. Doi: 10.1002/ (sici)1097-0274(199606)29:6<602:Aid-ajim4>3.0.Co;2-1

18 Compston A. Aids to the investigation of peripheral nerve injuries. Medical Research Council: Nerve Injuries Research Committee. His Majesty's Stationery Office: 1942; pp. 48 (iii) and 74 figures and 7 diagrams; with aids to the examination of the peripheral nervous system. By Michael O'Brien for the Guarantors of Brain. Saunders Elsevier: 2010; pp. [8] 64 and 94 Figures. Brain 2010; 133(10):2838-2844. Doi: 10.1093/brain/awq270

19 James MA. Use of the Medical Research Council muscle strength grading system in the upper extremity. J Hand Surg Am 2007;32 (02):154-156. Doi: 10.1016/j.jhsa.2006.11.008

20 Boonstra AM, Schiphorst Preuper HR, Reneman MF, Posthumus JB, Stewart RE. Reliability and validity of the visual analogue scale for disability in patients with chronic musculoskeletal pain. Int J Rehabil Res 2008;31(02):165-169. Doi: 10.1097/MRR.0b01 3e3282fc0f93

21 Myles PS, Myles DB, Galagher W, et al. Measuring acute postoperative pain using the visual analog scale: the minimal clinically important difference and patient acceptable symptom state. $\mathrm{Br} \mathrm{J}$ Anaesth 2017;118(03):424-429. Doi: 10.1093/bja/aew466

22 Midha R. Epidemiology of brachial plexus injuries in a multitrauma population. Neurosurgery 1997;40(06):1182-1188, discussion 1188-1189. Doi: 10.1097/0006123-199706000-00014

23 POLRI K. The Headquarter State Police of the Republic Indonesia Traffic Corps (POLANTAS) in. 2013 Accessed March 25, 2020. http://korlantas.polri.go.id/wpcontent/uploads/2015/10/PolantasDalamAngka2013.pdf

24 El-Gammal TA, El-Sayed A, Kotb MM, et al. Traumatic Brachial Plexus Palsy in Children: Long-Term Outcome and Strategy of Reconstruction. J Reconstr Microsurg 2021. Doi: 10.1055/s-00411726029

25 Elqazaz M, Elsebaey M. Traumatic Brachial Plexus Injuries: Epidemiological Study at two Egyptian Centers over 2 Years. Egyptian Spine Journal 2016;19(01):18-26. Doi: 10.21608/esj.2016.4010

26 Oliveira CM, Malheiros JA Moreira LdA, et al. Epidemiologic Profile of Brachial Plexus Traumatic Lesions in Adults at an Outpatient Clinic in Minas Gerais. Perfil epidemiológico das lesões traumáticas do plexo braquial em adultos atendidos em ambulatório de referência em Minas Gerais. Arquivos Brasileiros de Neurocirurgia: Brazilian Neurosurgery 2016;35(03):193-196 Doi: 10.1055/s-0036-1581082

27 Adeleye AO, Clark DJ, Malomo TA. Trauma demography and clinical epidemiology of motorcycle crash-related head injury in a neurosurgery practice in an African developing country. Traffic Inj Prev 2019;20(02):211-215. Doi: 10.1080/15389588.2018.1553085

28 Kandenwein JA, Kretschmer T, Engelhardt M, Richter H-P, Antoniadis G. Surgical interventions for traumatic lesions of the brachial plexus: a retrospective study of 134 cases. J Neurosurg 2005;103(04):614-621. Doi: 10.3171/jns.2005.103.4.0614

29 Leonard S, Woehrle T, Nikizad H, et al. Blunt traumatic brachial plexus injuries in a northern rural US setting: increased likelihood in unshielded motor-powered crashes. Trauma Surg Acute Care Open 2020;5(01):e000558. Doi: 10.1136/tsaco-2020-000558

30 Rhee PC, Pirola E, Hébert-Blouin MN, et al. Concomitant traumatic spinal cord and brachial plexus injuries in adult patients. J Bone Joint Surg Am 2011;93(24):2271-2277. Doi: 10.2106/jbjs.J.00922

31 Terzis JK, Kostopoulos VK. The surgical treatment of brachial plexus injuries in adults. Plast Reconstr Surg 2007;119(04):73e-92e. Doi: 10.1097/01.prs.0000254859.51903.97

32 Rasulić L, Savić A, Lepić M, et al. Epidemiological characteristics of surgically treated civilian traumatic brachial plexus injuries in Serbia. Acta Neurochir (Wien) 2018;160(09):1837-1845. Doi: 10.1007/s00701-018-3640-7

33 Cho ÁB, Guerreiro AC, Ferreira CHV, Kiyohara LY, Sorrenti L. Epidemiological study of traumatic brachial plexus injuries. Acta Ortop Bras 2020;28(01):16-18. Doi: 10.1590/1413785220202801224507

34 Bertelli JA, Ghizoni MF, Soldado F. Patterns of Brachial Plexus Stretch Palsy in a Prospective Series of 565 Surgically Treated Patients. J Hand Surg Am 2017;42(06):443-446.e2. Doi: 10.1016/ j.jhsa.2017.03.021

35 Adyaksa G, Suroto H. Apoptosis of proximal stump postganglionic brachial plexus injury, before and after six months post-trauma. Annals of Medicine and Surgery. 2021/03/01/ 2021;63:102156. Doi: 10.1016/j.amsu.2021.02.002

36 Dubuisson AS, Kline DG. Brachial plexus injury: a survey of 100 consecutive cases from a single service. Neurosurgery 2002;51 (03):673-682 discussion 682-683. Doi: 10.1227/00006123200209000-00011

37 Martin E, Senders JT, DiRisio AC, Smith TR, Broekman MLD. Timing of surgery in traumatic brachial plexus injury: a systematic review.J Neurosurg 2018;130(04):1-13. Doi: 10.3171/2018.1.Jns172068

38 Goldie BS, Coates CJ. Brachial Plexus Injury: A Survey of Incidence and Referral Pattern. J Hand Surg Br 1992;17(01):86-88. Doi: 10.1016/0266-7681(92)90018-w Available at: https://pubmed. ncbi.nlm.nih.gov/1322440/

39 Dy CJ, Baty J, Saeed MJ, Olsen MA, Osei DA. A Population-Based Analysis of Time to Surgery and Travel Distances for Brachial Plexus Surgery. J Hand Surg Am 2016;41(09):903-909.e3. Doi: 10.1016/j.jhsa.2016.07.054

40 Mackinnon SE. Future Perspectives in the Management of Nerve Injuries. J Reconstr Microsurg 2018;34(09):672-674. Doi: 10.1055/ s-0038-1639353

41 Oliver JD, Beal C, Graham EM, Santosa KB, Hu MS. Functioning Free Muscle Transfer for Brachial Plexus Injury: A Systematic Review and Pooled Analysis Comparing Functional Outcomes of Intercostal Nerve and Spinal Accessory Nerve Grafts. J Reconstr Microsurg 2020;36(08):567-571. Doi: 10.1055/s-0040-1713147

42 Carlson BM. The Biology of Long-Term Denervated Skeletal Muscle. Eur J Transl Myol 2014;24(01):3293. Doi: 10.4081/ejtm.2014.3293

43 Campbell WW. Evaluation and management of peripheral nerve injury. Clin Neurophysiol 2008;119(09):1951-1965. Doi: 10.1016/j. clinph.2008.03.018

44 Barrie KA, Steinmann SP, Shin AY, Spinner RJ, Bishop AT. Gracilis free muscle transfer for restoration of function after complete 
brachial plexus avulsion. Neurosurg Focus 2004;16(05):E8. Doi: 10.3171/foc.2004.16.5.9

45 Krauss EM, Tung TH, Moore AM. Free Functional Muscle Transfers to Restore Upper Extremity Function. Hand Clin 2016;32(02): 243-256. Doi: 10.1016/j.hcl.2015.12.010

46 Stiasny J, Birkeland P. Operative treatment with nerve repair can restore function in patients with traction injuries in the brachial plexus. Dan Med J 2015;62(03):A5038

47 Garg R, Merrell GA, Hillstrom HJ, Wolfe SW. Comparison of nerve transfers and nerve grafting for traumatic upper plexus palsy: a systematic review and analysis. J Bone Joint Surg Am 2011;93 (09):819-829. Doi: 10.2106/jbjs.I.01602

48 Ayhan E, Soldado F, Fontecha CG, Bertelli JA, Leblebicioglu G. Elbow flexion reconstruction with nerve transfer or grafting in patients with brachial plexus injuries: A systematic review and comparison study. Microsurgery 2020;40(01):79-86. Doi: 10.1002/micr.30440

49 Hems T. Nerve transfers for traumatic brachial plexus injury: advantages and problems. J Hand Microsurg 2011;3(01):6-10. Doi: 10.1007/s12593-011-0031-1

50 Bhandari PS, Sadhotra LP, Bhargava P, et al. Surgical outcomes following nerve transfers in upper brachial plexus injuries. Indian J Plast Surg 2009;42(02):150-160. Doi: 10.4103/0970-0358.59272
51 Weber RV, MacKinnon SE. Nerve transfers in the upper extremity. J Hand Surg Am 2004;4(03):200-213. Doi: 10.1016/j.jassh.2004.06.011

52 Swartz KR, Boland M, Fee DB. External neurolysis may result in early return of function in some muscle groups following brachial plexus surgery. Clin Neurol Neurosurg 2012;114(06):768-775. Doi: 10.1016/j.clineuro.2011.12.035

53 Potter SM, Ferris SI. Reliability of functioning free muscle transfer and vascularized ulnar nerve grafting for elbow flexion in complete brachial plexus palsy. J Hand Surg Eur Vol 2017;42(07): 693-699. Doi: 10.1177/1753193417702029

54 Koorevaar RCT, Kleinlugtenbelt YV, Landman EBM, van 't Riet E, Bulstra SK. Psychological symptoms and the MCID of the DASH score in shoulder surgery. Journal of Orthopaedic Surgery and Research. 2018/10/04 2018;13(01):246. Doi: 10.1186/s13018018-0949-0

55 Cheng H, Novak CB, Veillette C, von Schroeder HP. Influence of psychological factors on patient-reported upper extremity disability. J Hand Surg Eur Vol 2020;45(01):71-76. Doi: 10.1177/1753193419859373

56 Hadi MA, McHugh GA, Closs SJ. Impact of Chronic Pain on Patients' Quality of Life: A Comparative Mixed-Methods Study. J Patient Exp 2019;6(02):133-141. Doi: 10.1177/2374373518786013 